\title{
Strengthening flexural reinforced concrete beams using natural fiber reinforced polymer composite laminates
}

DOI:10.36909/jer.ACMM.16347

\author{
Manivel. $\mathrm{S}^{1}$ and Pannirselvam. $\mathrm{N}^{2}$ \\ ${ }^{1}$ Research Scholar, Assistant Professor, Department of Civil Engineering, SRM Institute of \\ Science and Technology, Kattankulathur, Tamilnadu, India - 603203. \\ ${ }^{2}$ Associate Professor, Department of Civil Engineering, SRM Institute of Science and \\ Technology, Kattankulathur, Tamilnadu, India - 603203. \\ ${ }^{2}$ Corresponding Author Email:pannirsn@srmist.edu.in .
}

\begin{abstract}
Fiber obtained naturally which is bio-degradable and extracted from plant species. Hibiscus Vitifolius Stalk Fiber (HVSF) when used in concrete increases the ductility for both new and old structures under specific treatment to avoid degradable. The application of fiber in the concrete structure is increased due to behavioural property of high tensile, high straining, high modulus, thermal resistance, low density, impact load resistance, non-toxic and good resistance to chemical attack. The flexural behaviour of the concrete is investigated and evaluated the optimum thickness of fiber in the soffit of the beam by eliminating delamination. The effectiveness of optimum thickness of fiber improved the ultimate load, ultimate deflection and improved in crack resistance.
\end{abstract}

Keywords: deflection, delamination, ductility, natural fiber, strength.

\section{INTRODUCTION}

Composites are distinct as two or more materials with different properties are combined into a single matrix reinforced and to attain desired shape. Their classification depends upon the addition of matrix with combining to chemicals, metal and ceramic composite matrix.

Fiber plays a major role for sustainable development, if extracted from stalk, root, seed, leaves etc. Maintenance of structure plays a major role in maintaining the monuments and to increase the life span of the structure which reduces the cost of new structure. The natural 
fiber provides benefits in cost, green, recyclable, biodegradable etc. Application of natural fiber includes in preparation of ropes, packing material, paper, textile industry, construction materials, aerospace application and in automobile sectors.

Natural fibers are used majorly as insulating materials due to its low mass, density and structure (Yinh et at., 2016). Earlier research carried out in plenty with carbon fiber reinforced concrete which is not sustainable but leads to higher strength and lesser in ductile property (Balamuralikrishnan \& Jeyasehar, 2009). Although the use of a cementitious matrix is common, the use of an epoxy strengthening adhesive was shown to be more efficient in terms of stress transmission. (Prota et at., 2016). The altering the thickness was investigated using the four point loading test (Barros \& Figueiras, 1999). Mechanical characteristics of composite carbon, composite glass sheets, and hybrid combinations are influenced by hybrid combinations. The failure mechanisms which occurs are also investigated (Subramaniam et at., 2007).

\section{OBJECTIVE OF THE STUDY}

The main objective of the study includes

1. Extraction of natural fibers from plant, to develop the woven as fabrics using natural fibers.

2. To develop the composite material and to progress the mechanical properties of natural fibers the chemical treatments used to modify the surface and reduces moisture absorption.

3. To study the increase in load carrying capacity of Reinforced Concrete (RC) rectangular beams on application of externally bonded Natural Fiber Reinforced Polymer (NFRP) laminates.

4. To study the load-deflection characteristic of NFRP bonded RC rectangular beam. 
5. To study the variation in strain pattern due to the presence of surface mounted NFRP laminates

6. To study the level of reduction in crack width in FRP strengthened RC rectangular beams compared to their unplated beams.

\section{METHOD/EXTRACTION OF FIBER}

The greenhouse effect has inspired to use natural fiber as an alternative to synthetic fiber in the construction, automotive and packing industries (Silva et al., 2008). Natural fibers available in fibrous form which is of low cost extracted from plant species. The plants were found in the region of Potheri village, Chengalpattu district, Tamil Nadu, India. With a sharp blade, the stalks of Hibiscus Vitifolius plants were cut into desired lengths and immersed in water for 2 weeks for microbial degradation, and during this time, the outer layer becomes soft, so that the fibers can be separated easily (Fig.1) by water/microbial retting (Gopinath et al., 2016). The fibers were then washed and dried in the sun for 24 hours to remove moisture. In this research chemical analysis like cellulose, hemicellulose, wax, lignin and ash content were examined through standard test method. The test results reveal the fiber as high crystalline index than other fibers which was conformed through XRD analysis (Saravanakumar et al., 2017).
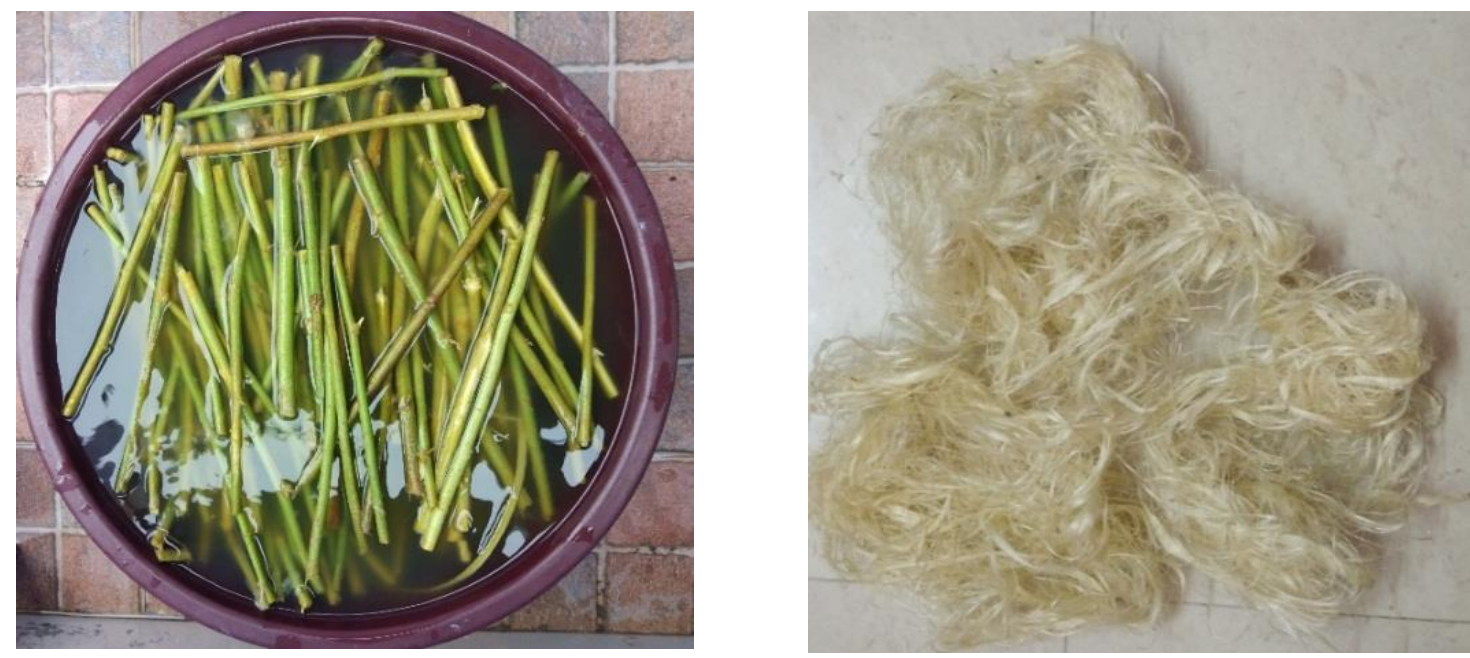
Figure 1. Soaking process and extracted raw fiber

\section{ALKALI TREATMENT}

In the beginning, the alkali solution is prepared at different concentrations like $2 \%$ to $8 \%$. Then, extracted raw fibers are immersed in the alkali solution for an hour. The fibers are then washed repeatedly with tap water and distilled water to neutralize the $\mathrm{pH}$. After this step, the fiber was washed with acetic acid in order to remove excess alkaline from it. The chemically treated fiber showed an increase in crystalline with a decrease in other chemical components (Venugopal \& Boominathan, 2020). Then the treated fiber was converted into yarn form. In the yarn formation process the fibers are arranged into mat (Yan et al., 2012) and presented in figure 2 .
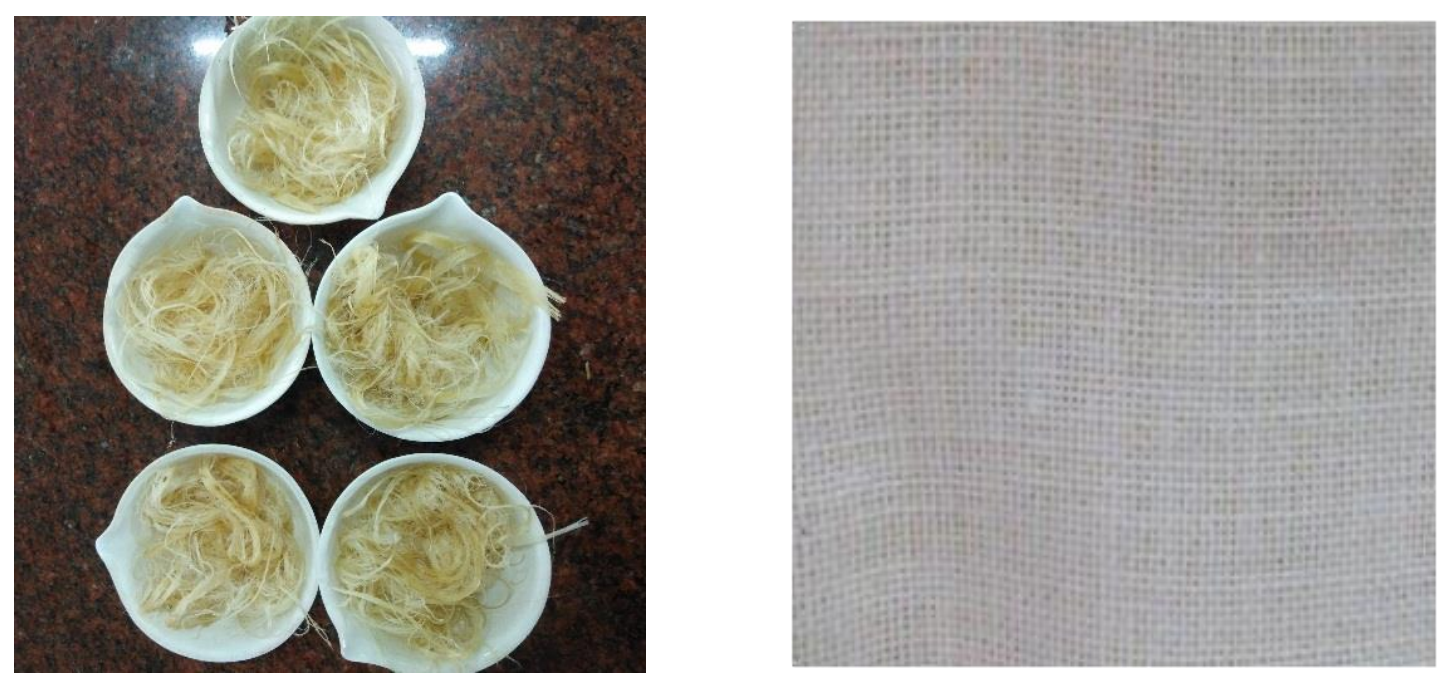

Figure 2. Treated and matform of hibiscus vitifolius fiber

\section{MATERIALS USED}

Cement: The locally available cement of 53 PPC used for testing its physical properties and for casting of specimens.

M-Sand: M-Sand available from the nearby quarry used for evaluating its physical properties and for casting of specimens. 
Coarse aggregate: The coarse aggregate obtained from nearby source and $20 \mathrm{~mm}$ aggregate of $60 \%$ and $10 \mathrm{~mm}$ aggregate of $40 \%$ used for casting the specimen after determining its physical properties. The properties of cement, M-Sand and coarse aggregate are presented in table 1 .

Table 1. Properties of materials used

\begin{tabular}{|c|c|c|c|c|}
\hline S. No. & Property & Cement (53 grade) & M-Sand & Coarse aggregate \\
\hline 1 & Specific gravity & 3.15 & 2.55 & 2.83 \\
\hline 2 & Fineness & 91.8 & - & - \\
\hline 3 & Consistency & $32 \%$ & - & - \\
\hline 4 & Initial setting time & 68 min & - & - \\
\hline 5 & Final setting time & 338 min & - & - \\
\hline 6 & Fineness modulus & $5 \%$ & 3.15 & 6.50 \\
\hline 7 & Water absorption & - & $0.5 \%$ & 0.52 \\
\hline 8 & Particle shape & - & - & Angular \\
\hline 9 & Impact value & - & - & 13.50 \\
\hline 10 & Crushing value & - & - & 18.80 \\
\hline 11 & Zone & - & III & - \\
\hline
\end{tabular}

Concrete: The concrete prepared from the initial tests carried out after determining the physical properties of materials. Mix design proportion arrived as per IS 10262 and evaluated the concrete strength in its fresh and hardened state for M30 grade of concrete.

Natural fiber: Natural fiber extracted from the stalk of hibiscus vitifolius by water retting process (Manivel et al., 2021) used for laminating reinforced concrete beam at the soffit of the beam with epoxy adhesive. By using epoxy adhesive ensured that delamination process does not occur in due course and their properties are presented in table 2. 
Table 2. Properties of natural fiber

\begin{tabular}{|c|c|c|}
\hline S. No. & Property & Values \\
\hline 1 & Crystalline index & 67.07 \\
\hline 2 & Tensile strength (MPa) & $224.32-716.70$ \\
\hline 3 & Tensile modulus $(\mathrm{GPa})$ & $16.03-39.85$ \\
\hline 4 & Elongation $(\%)$ & $3.99-8.77$ \\
\hline 5 & Density $\left(\mathrm{kg} / \mathrm{m}^{3}\right)$ & 1530 \\
\hline
\end{tabular}

\section{MORPHOLOGICAL ANALYSIS}

Scanning Electron Microscope (SEM) images examines the morphology of fiber surface. On investigation on the fiber through this process the images clearly predict the presence of impurities in the outermost surface and hence this doesn't allow to bond with other materials in the untreated fiber. By alkali treatment, eliminates the impurities which causes loss of adhesion in bonding and improves the mechanical properties for developing application in composites are presented in figure 3.
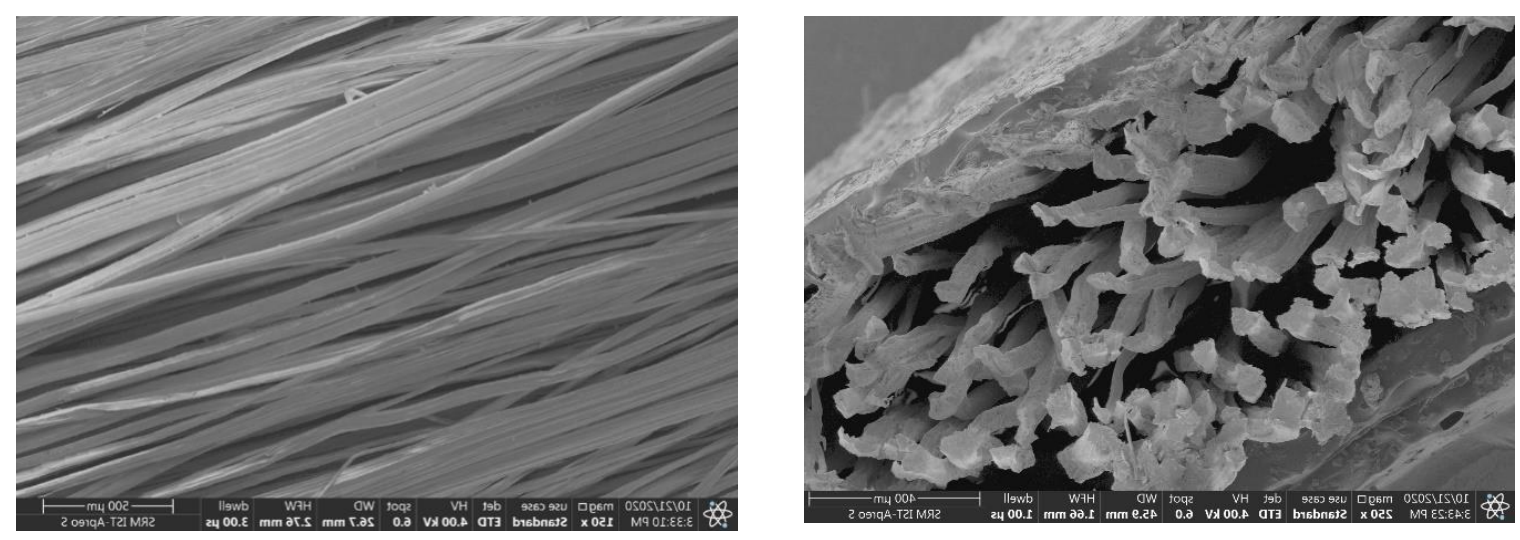

Figure 3. SEM anlaysis of untreated and treated hibiscus vitifolius stalk fiber

\section{BEHAVIOUR OF FIBER REINFORCED POLYMER}

The advantage of using composites strengthens the structure. The composite is strong in the direction of fiber added which may be in plate or wrapped over the structure. Fiber 
Reinforced Polymer (FRP) drive of higher live or dead load without increasing their dead load since the thickness varies very less than $5 \mathrm{~mm}$.

\section{EXTERNALLY BONDED FRP FOR STRUCTURAL STRENGTHENING}

FRP may be used to reinforce structural members such as beams, columns, slabs, and masonry walls (Pannirselvam et al., 2008). FRP strips can be used to strengthen beams and slabs. Vertical or inclined strips of FRP used for shear strengthening of beams. Wrapping a U-shape across the cross section of beams allows for the retention of both flexure and shear.The concrete beams strengthened with natural fiber to evaluate the flexural behaviour of RCC beams with externally bonded FRP (Arun et al., 2017). The process of grinding, cutting and adhering to the beam with NFRP are presented in figure 4.
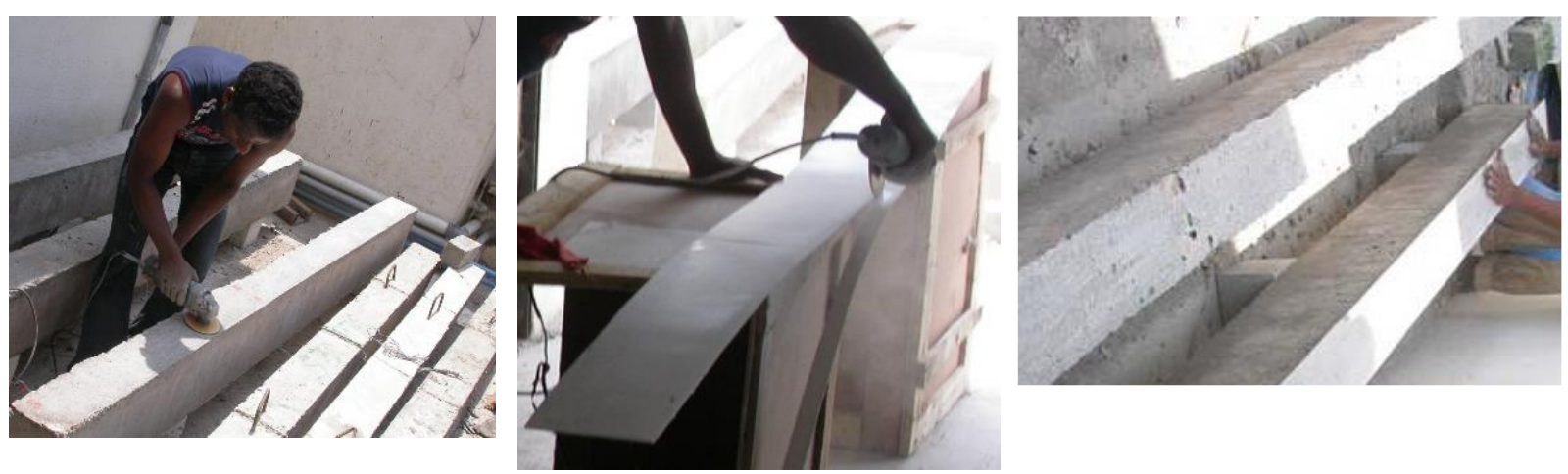

Figure 4. Process of grinding, cutting and adhering to beam

\section{EXPERIMENTAL PROCEDURE}

The beams strengthened with FRP material and plain beams without FRP materials were tested by four-pointbending. The experimental setup is shown in figure 5 .

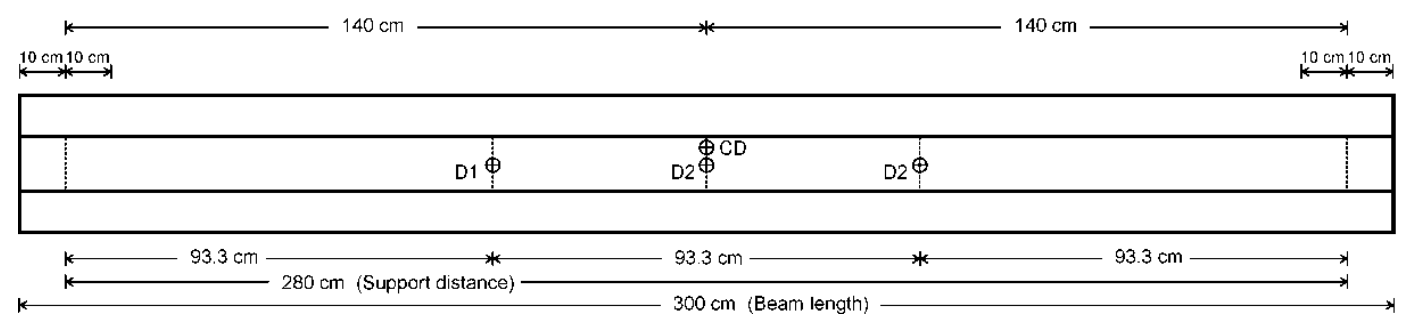

Figure 5. Position of gauges to measure the deflection 
The first crack load, yield and ultimate load with their respective were determined in the loading frame of $50 \mathrm{t}$ capacity in figures 6-8. The crack width at yield and maximum were evaluated and presented in table 3. NFRP1 represents the one layer of extracted natural fiber laminated in the soffit of the beam.

Table 3. Load, deflections and crack width at stages

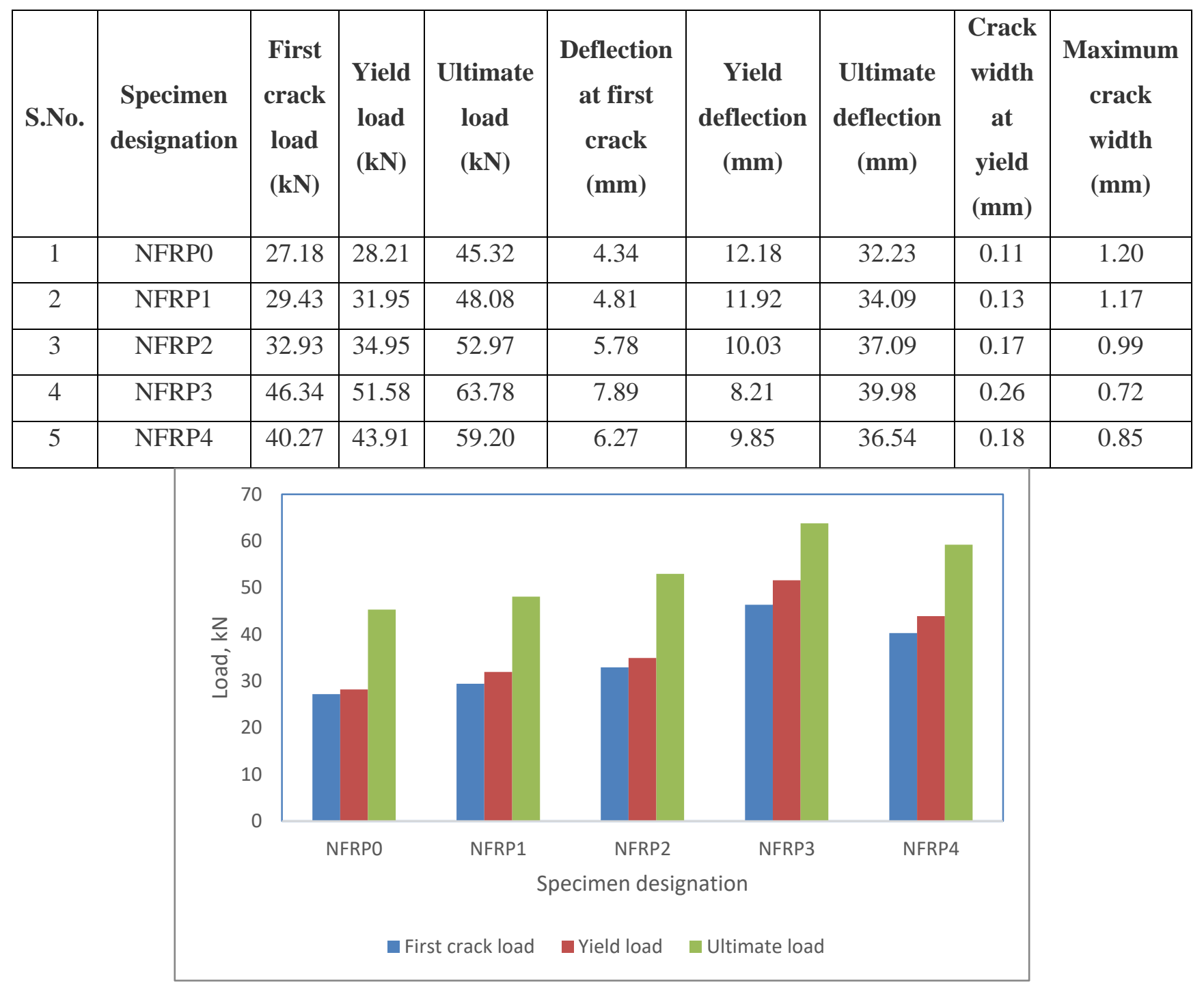

Figure 6. Load carrying capacity of the beams 


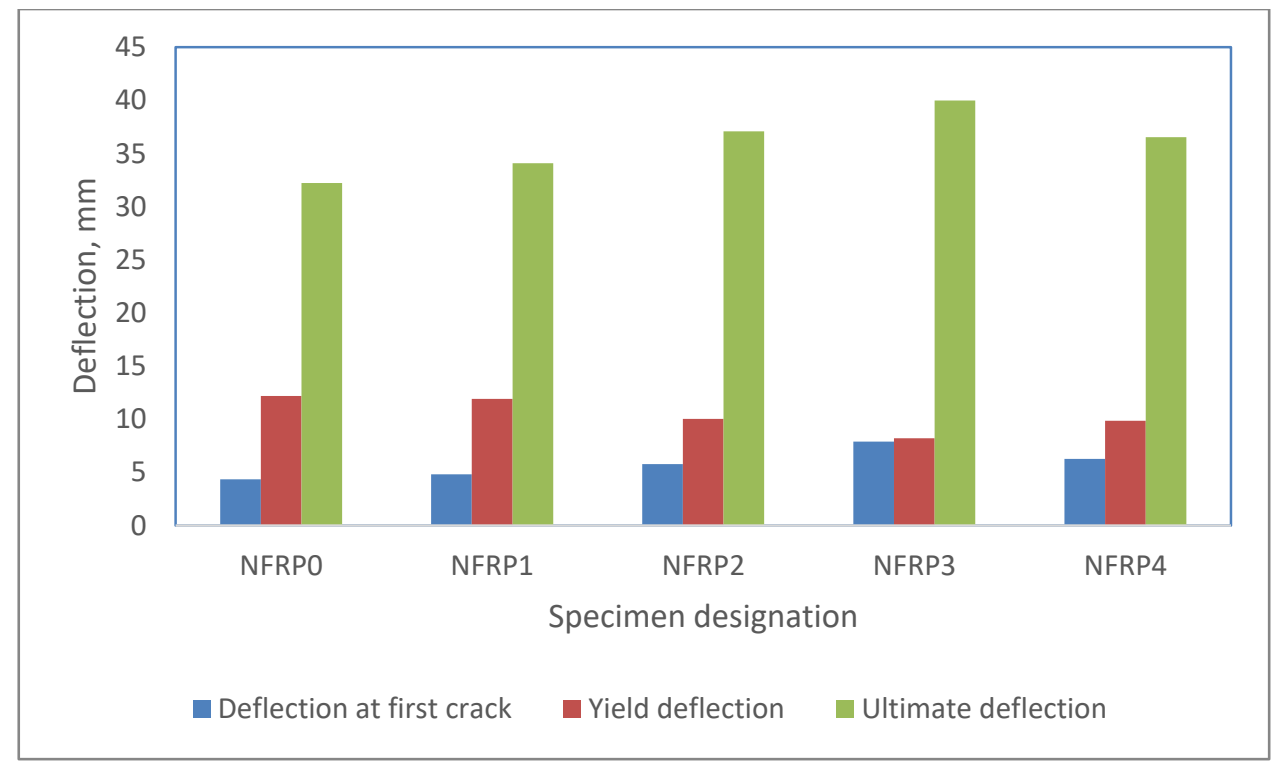

Figure 7. Deflection of the beams

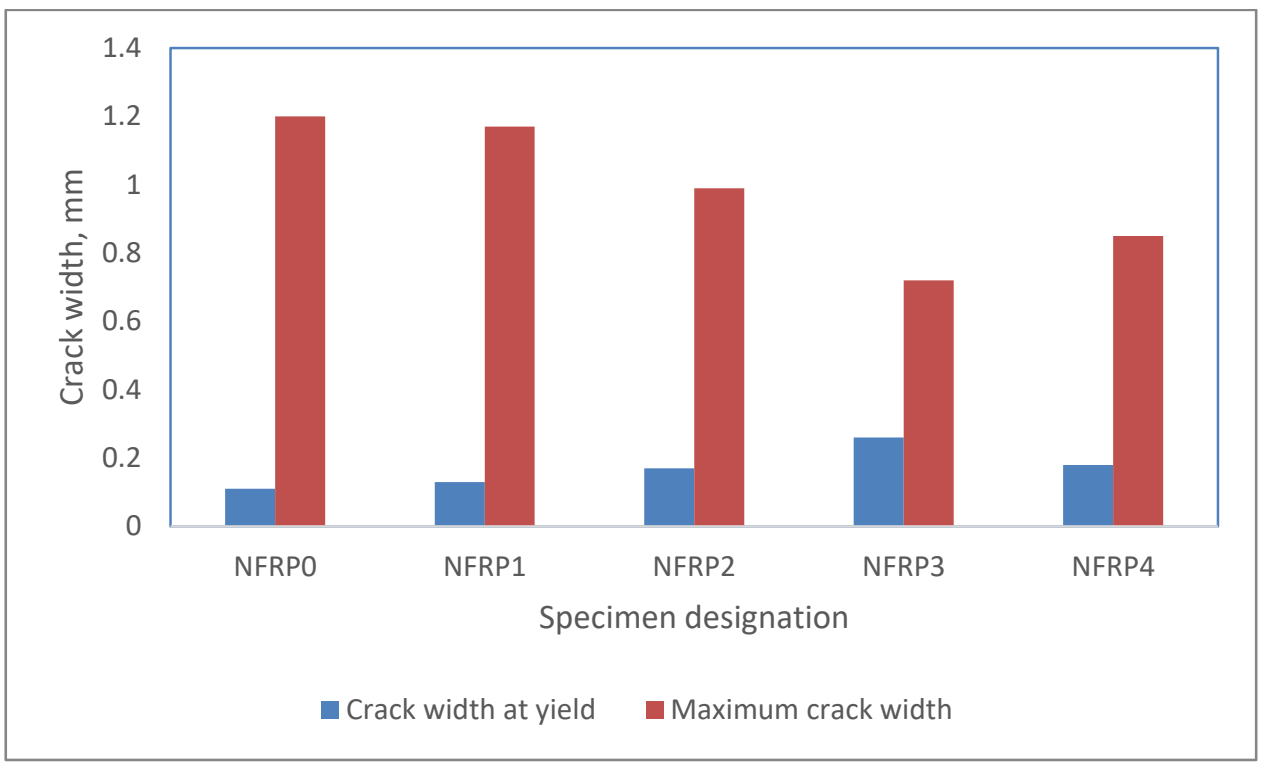

Figure 8. Crack width of the beam

\section{CONCLUSION}

The conclusions are arrived based on the experimental data.

a) The NFRP plating showed higher improvement in first crack load.

b) The deflections at which first cracks appeared at the tension zone of the beams were higher for NFRP plated beams.

c) Permissible service loads increased due to the increase in stiffness and reduction in crack width values. 
d) Yield loads increased substantially due to the bonding of NFRP plates.

e) Yield deflection values were marginally lower for NFRP plated beams compared to the unplated beams.

f) The ultimate loads reached by the NFRP plated beams were higher than those reached by the unplated specimens.

g) The ultimate load achieved at NFRP1, NFRP2, NFRP3 and NFRP4 plated beams are $48.08,52.97,63.78$ and $59.20 \mathrm{~N} / \mathrm{mm}^{2}$.

h) NFRP3 plating resulted in substantially higher ultimate load levels of $40.73 \%$ compared to NFRP0.

i) The maximum crack width reduced to $40 \%$ with reference to control specimen without natural fiber.

j) There was increase in the ultimate deflection of the NFRP plated beams. But, the increase in deflection ultimate deflection was very low compared to the heavy increases shown in ultimate strength.

\section{REFERENCES}

Arun Vignesh, S., Sumathi, A. \& Saravana Raja Mohan, K. 2017. Flexural behaviour of RCC beams with externally bonded FRP. IOP Conference Series: Earth and Environmental Science, 80,1-14.

Balamuralikrishnan, R. \& Jeyasehar, C. A. 2009. Flexural behavior of RC beams strengthened with carbon fiber reinforced polymer fabrics. The Open Civil Engineering Journal, 3, 102-109.

Barros, J.A.O. \& Figueiras, J.A. 1999. Flexure behavior of SFRC: Testing and modeling, Journal of Material Civil Engineering, 11(4), 331-339.

Gopinath, R., Ganesan, K., Saravanakumar, S.S. \& Poopathi, R. 2016. Characterization of new cellulosic fiber from the stem of Sida rhombifolia. International Journal of Polymer Analysis and Characterization, 21, 123-129.

Manibalan, P., Baskar, R. \& Pannirselvam, N. 2020. Flexural behaviour of reinforced 
concrete beam using basalt fiber, International Journal of Mechanical and Production Engineering Research and Development, 10(3), 16055-16064.

Manivel, S., Pannirselvam, N., Gopinath, R. \& Sathishkumar, T.P. 2021. Physicomechanical, chemical composition and thermal properties of cellulose fiber from hibiscus vitifolius plant stalk for polymer composites. Journal of Natural Fibers, 1, 116.

Murali, G. \& Pannirselvam, N. 2011. Flexural strengthening of reinforced concrete beams using fibre reinforced polymer laminate: a review, ARPN Journal of Engineering and Applied Sciences, 6(11), 41-47.

Pannirselvam, N., Nagaradjane, V. \& Chandramouli, K. 2009. Strength behaviour of fibre reinforced polymer strengthened beam, ARPN Journal of Engineering and Applied Sciences, 4(9), 34-39.

Pannirselvam, N., Ragunath, P.N. \& Suguna, K. 2008. Strength and ductility of fibre reinforced polymer plated RC beams, International Journal of Applied Engineering Research, 3(7), 999-1018.

Pannirselvam, N., Ragunath, P.N. \& Suguna, K. 2008. Strength modeling of reinforced concrete beam with externally bonded FRP reinforcement, American Journal of Engineering and Applied Sciences, 1(3), 192-199.

Prota, A., Tan, KY., Nanni Pecce, M. \& Manfredi, G. 2016. Performance of Shallow Reinforced Concrete Beams with Externally Bonded Steel-Reinforced Polymer, ACI Structural Journal, 103, 163 - 170.

Salih, Y.A., Sabeeh, N.N., Yass, M.F., Ahmed, A.S. \& Khudhurr, E.S. 2019. Concrete beams strengthened with jute fibers. Civil Engineering Journal, 5, 767-776.

Saravana Kumaar, A., Senthilkumar, A., Sornakumar, T., Saravanakumar, S.S. \& Arthanariesewaran, V.P. 2017. Physicochemical properties of new cellulosic fiber extracted from carica papaya bark, Journal of Natural Fibres, 16, 175-184.

Silva, F. de A., Chawla, N. \& Filho, R.D. de T. 2008. Tensile behavior of high performance natural (sisal) fibers. Composites Science and Technology, 68, 3438-3443.

Subramaniam, K.V., Carloni, C \& Nobile, L, 2007. Width effect in the interface fracture during shear bonding of FRP sheets from concrete, Engineering Fracture Mechanics, 74, 578-594. 
Venugopal, A. \& Boominathan, S.K. 2020. Physico-chemical, thermal and tensile properties of alkali-treated acacia concinna fiber. Journal of Natural Fibers, 1-16.

Yan, L., Chouw, N. \& Yuan, X. 2012. Improving the mechanical properties of natural fibre fabric reinforced epoxy composites by alkali treatment. Journal of Reinforced Plastics and Composites, 31, 425-437.

Yinh, S., Hussain, Q., Rattanapitikon, W. \& Pimanmas, A. 2016. Flexural behavior of reinforced-concrete beams strengthened with hemp fiber-reinforced polymer composites. Materials Science Forum, 860, 156-159. 